\title{
Result and Analysis of Implemented Real Time Wireless Health Monitoring System Using Sensors
}

\author{
Mayuri Malke ${ }^{1}$, Asst. Prof.Sheeja S. Suresh ${ }^{2}$ \\ ${ }^{1}$ M.TECH student (VLSI design), Department of Electronics \& Telecommunication Engineering \\ G.H. Raisoni Institute of Engineering and Technology for Women, Nagpur \\ ${ }^{2}$ Assistant Professor, Department of Electronics \& Telecommunication Engineering G.H. Raisoni Institute of \\ Engineering and Technology for Women, Nagpur
}

\begin{abstract}
This purposed paper based on wireless health monitoring system which is real time. Wireless Health Monitoring System (WHMS) is system in which body parameter of patient are sensed by sensor which are connected to the patient's body. When The body parameter of patient senesced by sensors are in the normal range (Below threshold value)it will transferred to Nurse control station on real time using transreceiver models having different range according to model. Nurse control station data transferred to doctor's smart phone using internet on real time . There is bidirectional data transfer between doctor's smart phone and nurse control station. On the other side when the body parameter of patient senesced by sensors are above the normal range(above threshold value )then gives alert message to doctor's smart phone as well as ambulance using GSM module and also transmit data from local site to remote monitoring site. The main goal of system is to provide efficient wireless health monitoring in normal cases as well as in emergency cases.
\end{abstract}

Keywords: Trans receiver model, sensors, GSM module memory card, smart phone .

\section{Introduction}

As of late, the quick improvement of remote systems has prompted the crisis of another sort of e-social insurance framework, giving master built medicinal medication remotely with respect to time. With the emedicinal services framework, wearable sensors and versatile remote gadgets can naturally screen people's wellbeing status and forward them to the doctor's facilities, specialists and related individuals. The framework offers incredible accommodations to both patients and health awareness suppliers Present day advanced mobile phones are IP empowered gadgets that can get to the Internet through various remote interfaces. These interfaces are ordinarily Bluetooth, WLAN and $3 g$ (through Mobile PSTN).

As of late, $4 \mathrm{G}$ interfaces, for example, LTE are accessible on advanced cells. The greater part of these telephones likewise have ready for their utilization. Advanced cell clients are portable and their current need is to have entry to the Internet at all times even while they are moving. Versatile IP encourages this need. Then again, the accessibility of Mobile IP help on supplier organizes and additionally on end client gadgets is a worry. Human services are the application zone that we consider in the setting of versatile information access. One of the numerous essential needs to administer forethought, be it preventive consideration or after forethought is availability to the patient information for determination.

Quiet information comprises of the restorative history of the patient and incorporates information relating to the late disease and medicine on account of after forethought. Our centre is on giving access of such patient information to a specialist who is versatile (wandering crosswise over access systems). The specialist ought to have the capacity to get to the measured sensor information persistently through the web server from the patient databases in remote observing webpage and accept alarm message as SMS when the measured sensor qualities beat the set limit values progressively at the neighbourhood website. Throughout such get to, there ought to be no irregularity in the right to gain entrance from the specialist to the information she/he is getting to. 
2.1 Block Diagram

\section{Methodology}

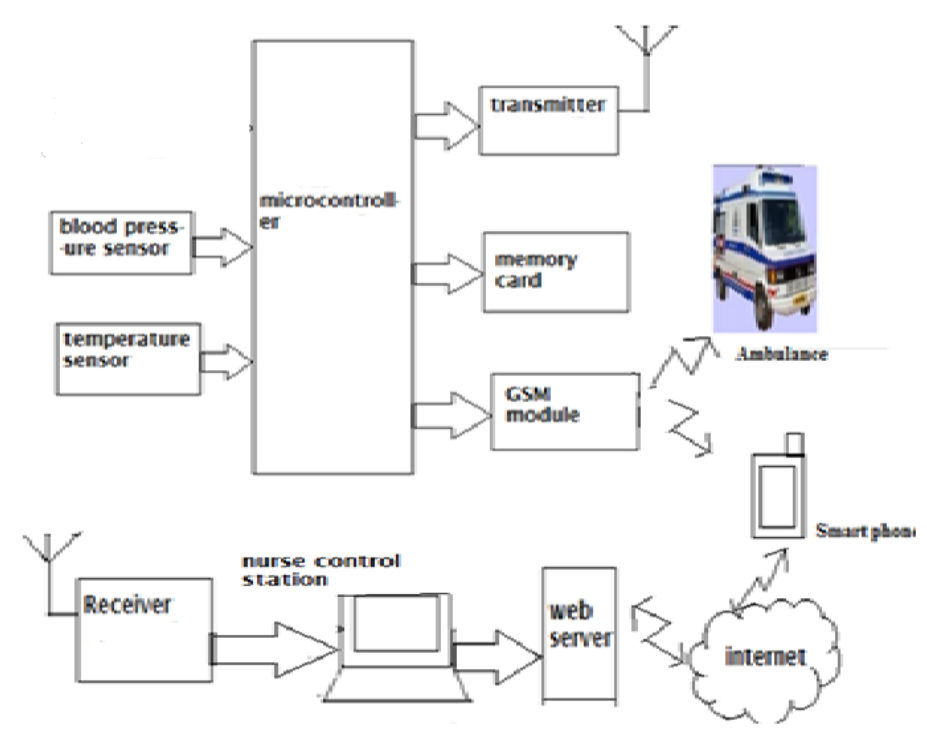

Figure: Block Diagram

The block diagram of project is as shown in the figure 3.1. The project "Design and Implementation of Real Time Wireless Health Monitoring System using Sensors" is divided into two subsystems,

A. Local (Patient) site

B. Remote Monitoring (Nurse Control Station) site

\section{Local (Patient) site:}

In this system patient site is referred as local site. Here, sensors are connected to patient's body which senses the physical parameters of patient's body and transmit the measured value to the remote monitoring site which contains different units like nurse station, doctor's smart phone and ambulance etc.

Local site consists of different units like sensors; ARM controller, Memory card, GSM module and transmitter (CC2500). Sensors like BP sensor and Temperature sensor are used to senses the patient's body parameters, in the analog form, which are given to the ARM microcontroller (LPC2148) which contain inbuilt analog to digital convertor which converts the analog values into digital values. ARM microcontroller gives digital values of the sensed data as output, details are as given below:

1. Digital values from ARM microcontroller transmitted through transmitter (CC2500) to Nurse Station. At the same time these digital values are stored in memory card for future use.

2. Digital values are also given to the GSM module when the values cross threshold level.

\section{Remote monitoring site:}

The Receiver site is referred as Nurse Control Station, which receives data from local site (Patient site). Receiver receives data transmitted from the local site and gives it to FT which is connected to the Nurse Station. FT is used to convert serial data into USB data. Data of the patient is stored in data base of nurse station as well as transmitted to the doctor's Smartphone.

\section{Result}

According to the proposed plan and design platform, this project is implemented using ARM7 processor, sensors, GSM module, Transreceiver module (CC2500) and memory card. The complete system helps to solve the problem of daily health check up and emergency condition as well as it helps to create communication between patient and doctor.

- When the power is switched on. The system is initialized and the name display on the LCD display is "Wireless Health Monitoring System" [Refer Figure 4(b)].

- A sensor connected to patient's body, senses the body parameters like systolic and diastolic pressure, Temperature and Heart rate and gives analog output to the microcontroller (LPC2148).

- LPC2148 consist of in built analog to digital convertor therefore the analog values are converted into digital values using analog to digital convertor. Digital values display on the LCD screen [Refer figure 4(a)]. The working of system consists of two cases. 
- In first case, the microcontroller gives the digital values of sensed parameters. If the given values are below threshold level then microcontroller normally transmits the output using transmitter (CC2500) from local site to remote monitoring site. At the same time the output is stored in the memory card for the future use.

- On remote monitoring site values are received by receiver $(\mathrm{CC} 2500)$ which gives the output to FT then FT converts serial data into USB data which is shown at Nurse Control Station. The output is displayed on GUI screen[Refer Figure1] as well as it is stored in database for future use and doctor can see the database on his/her mobile using internet.

- When the doctor wants to see the data of the patient he/she can see all databases using www.jobility.com site on his Smartphone [Refer Figure 2(a)].

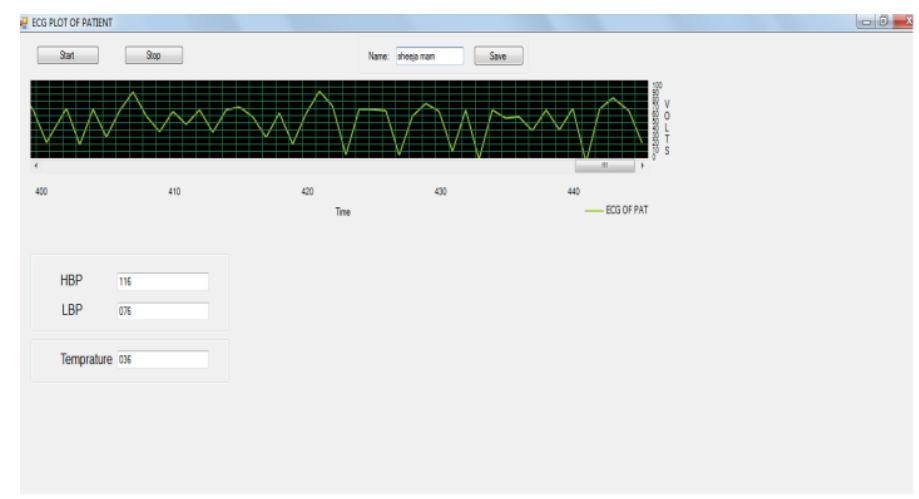

Figure 1 Display output on GUI

- In second case, if the digital values exceed the threshold values then GSM module is used for emergency SMS alert. GSM module sends an emergency SMS alert to the doctor's Smartphone as well as to the ambulance. The SMS alert to doctor's Smartphone shown in figure 2(b).

- At same time the output is stored in the memory card for the future use. On remote monitoring site values are received by receiver (CC2500) and gives output to FT then FT convert serial data into USB data which is shown at Nurse Control Station. The output is displayed on GUI screen as well as it is stored in database for future use and doctor can see the database on his/her mobile using internet.

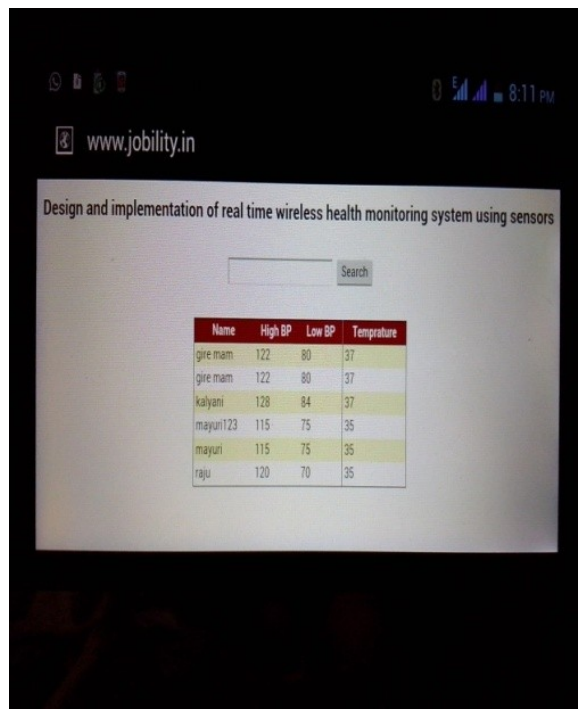

Figure 2(a) Database of Patient's data

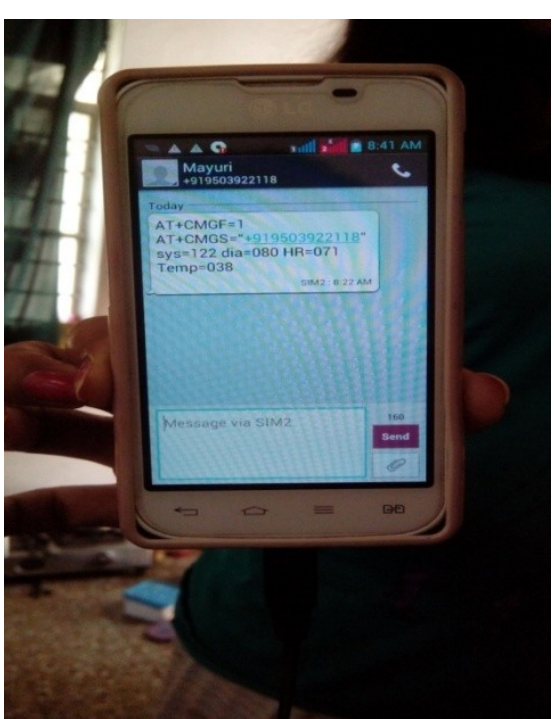

Figure 2(b) SMS alert on doctor's cell phone

The Top view of complete system shown below in Figure 


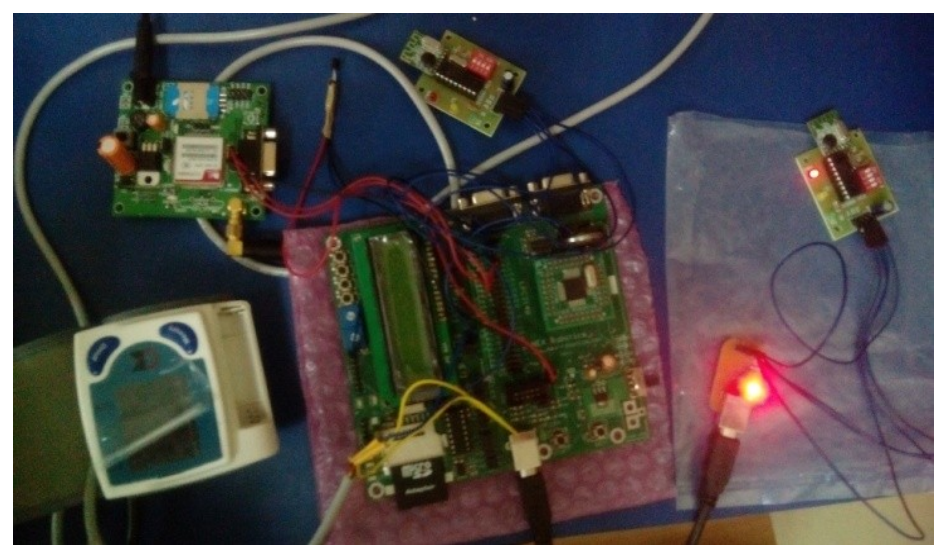

Figure 3: Project Top view of wireless health monitoring system

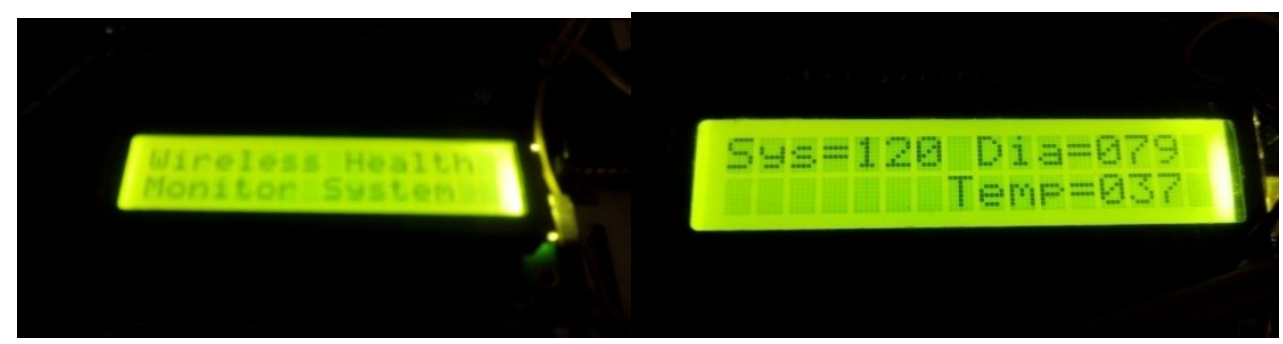

Figure 4(a). System name display on LCD Figure 4(b).LCD display [Digital output]

\section{Conclusion}

1. This implemented project deals with finding the technical and advance solution to a major problem at hospital like monitoring the patient conditions online.

2. This project is expected to spread wide awareness on how technology can be used in emergency cases.

3. It is portable, real time system.

4. This implemented project deals with finding solution of taking patient's body reading like heart rate, pressure of Body and temperature using BP sensor and Temperature sensor.

5. Designed Remote monitoring site receives data from local site using receiver in normal cases as well as in emergency cases and forward data to doctor's Smartphone.

6. This implemented project provides solution for emergency condition by sending an SMS alert to Doctor's Smartphone as well as Ambulance.

\section{Future Scope}

This implemented project deals with finding the technical and advance solution to a major problem at hospital like monitoring the patient condition online and expected to spread wide awareness on how technology can be used in emergency cases. This system is portable and real time system. Wearable sensors can be used for better health monitoring system. Different types of wireless sensors can be used to increase the level of monitoring.

This implemented project upgraded for a wireless emergency telemedicine system. Other physical parameters can be added according to requirement like for position of patient, sugar level detection etc. Remote health monitoring improves quality of care, reduces healthcare spend and empowers patients. This project upgraded for wireless space maker by adding GPRS module so that the location of patient can be easy detected and one another way to upgrade project by wireless ECG monitoring on the computer using Zigbee technology.

\section{References}

[1]. Baba Prasad G, Seema K, Shrikant U H, Gopi Krishna Garge, Anand S V R and Malati Hegde "SeaMo+: A Virtual Real-time Multimedia Service Framework on Handhelds to enable Remote Real-time Patient Monitoring for Mobile Doctor"978-1-46735494-3/13.

[2]. Xiaohui Liang, Mrinmoy Barua, Le Chen, Rongxing Lu, Xuemin(Sherman) Shen "Enabling Pervasive Healthcare through Continuous Remote Health Monitoring" 1536-1284/12

[3]. Namrata Nawka, Anil Kumar Maguliri, Dhirender Sharma, Preeti Saluja "SESGARH: A Scalable Extensible Smart-Phone based Mobile Gateway and Application for Remote Health Monitoring" 978-1-4577-1328-6/11

[4]. Hongzhou Yu, Lu Liu "Remote Health Monitoring System Using ZigBee Network and GPRS Transmission Technology" 978-0$7695-4500-4 / 11$ 
[5]. Dr.(Mrs).R.Sukanesh, P.Gautham,P.T.Arunmozhivarman, S.Palanivel rajan,S.Vijayprasath "Cellular Phone based Biomedical System for Health Care" 978-1-4244-7770-8/10

[6]. Wan-Young Chung, Chiew-Lian Yau, Kwang-Sig Shin, and ksto Myllyla Member “A Cell Phone Based Health Monitoring System with Self Analysis Processor using Wireless Sensor Network Technology" 1 -4244-0788-5/07

[7]. J. H. Hong, J.M. Kim, E. J. Cha, T. S. Lee "A wireless 3- channel ECG transmission system using PDA phone" 0-7695-3038-9/07

[8]. Balakrishna D, Sujeethnanda M, Dr. G. Rama Murthy, "Mobile Wireless Sensor Networks: Healthcare in Hospitals", ifth International Conference on eHealth, Telemedicine, and Social Medicine(eTELEMED 2013)

[9]. Mrs. Rajashri Patil , Prof.Balaji Hogade "On Line Real Time Health Monitoring of ICU Patients using ARM7" International Journal of Computer Science and Network (IJCSN) Volume 1, Issue 3, June 2012. 